\title{
Earlier use of capsule endoscopy in inpatients with melena or severe iron deficiency anemia reduces need for colonoscopy and shortens hospital stay
}

(1) $\odot \ominus$

\author{
Authors \\ Diana E. Yung, Anastasios Koulaouzidis, Sarah Douglas, John N. Plevris
}

Institution

Centre for Liver \& Digestive Disorders, The Royal Infirmary of Edinburgh, Edinburgh, United Kingdom

submitted 18.8.2017

accepted after revision 7.3 .2018

Bibliography

DOI https://doi.org/10.1055/a-0640-2956 |

Endoscopy International Open 2018; 06: E1075-E1084

(c) Georg Thieme Verlag KG Stuttgart · New York

ISSN 2364-3722

Corresponding author

Diana E. Yung, MBChB, Endoscopy Unit, The Royal Infirmary

of Edinburgh, 51 Little France Crescent, EH16 4SA

Fax: +07789588408

diana.e.yung@gmail.com

\section{ABSTRACT}

Background and study aims Capsule endoscopy(CE) is a well-established investigation for iron deficiency anemia (IDA) and melena, usually following negative upper and lower endoscopy. We aimed to study the effect of earlier CE in the investigative pathway for inpatients with IDA or melena at a large tertiary referral centre.

Patients and methods We analyzed inpatients undergoing CE for IDA or melena from 2005 to 2017, without signs/ symptoms suggesting lower gastrointestinal tract pathology. Patients underwent CE following negative upper and lower gastrointestinal endoscopy (Group 1), or negative upper gastrointestinal endoscopy (UGIE) only (Group 2).

Results One hundred and seventy inpatients underwent CE for IDA $(n=44)$ and melena $(n=126)$. In Group 1, 46/95 (48.4\%) patients had small bowel (SB) findings. CE found $16 / 95(16.8 \%)$ gastric and 12/95 (12.6\%) colon findings. Three of 12 patients with colon findings required repeat colonoscopy. One hundred and three colon investigations were carried out for 95 admissions. In Group 2, 33/75 (44.0\%) patients had SB findings. There were 12/75 (16.0\%) gastric and 11/75 (14.7\%) colon findings. In patients with positive $\mathrm{CE}$, significant colonic findings led to colonoscopy in 10 of 39 patients (diagnostic yield 6/10). Thirty-six patients had negative CE; 15 underwent colonoscopy (diagnostic yield 9/15). The remaining 21 of 36 patients with no further colonoscopy did not develop adverse outcomes related to colonic pathology. Twenty-six colon investigations were carried out in 75 admissions. Patients in Group 2 had shorter mean times from admission to CE $(5.08 \pm 3.80$ vs. $6.38 \pm 3.80$ days; $P=0.02)$ and hospital stays $(10.5 \pm 9.58$ vs. $12.5 \pm 11.4$ days; $P=0.04)$ compared to Group 1 .

Conclusion Earlier use of CE in inpatients with melena or IDA, no signs of lower gastrointestinal pathology and negative UGIE resulted in shortened hospital stays, significant DY from both small bowel and upper gastrointestinal tract, and two-thirds less unnecessary colon investigations without affecting clinical outcomes.

\section{Introduction}

Capsule endoscopy (CE) is well-established for investigation of small bowel bleeding [1], often presenting as iron deficiency anemia (IDA) or melena [2,3]. CE is usually performed nonacutely as an outpatient procedure; however, there is now evidence that performing CE closer to the index bleeding episode increases its diagnostic yield (DY). Recent work suggests that in small bowel bleeding, the maximum DY for CE is achieved within the first 72 hours of presentation [4]. This is corroborated by studies showing that for the same indications, inpatient
CE has a higher DY compared to outpatient procedures [5-7]. However, there is overall scarce data on inpatient use of $C E$ ( Table 1).

Although current practice varies, official guidelines generally suggest performing $C E$ in patients presenting acutely with suspected small bowel bleeding after negative upper and lower gastrointestinal endoscopy (i.e. negative bidirectional endoscopy). However, performing colonoscopy in the acute setting is a demanding task both for the patient and clinician, and is often limited by the quality of bowel preparation and patient fitness or tolerance. At our large tertiary care hospital, there has 
been a trend for performing CE following a negative index upper gastrointestinal endoscopy (UGIE), with anecdotal evidence that by doing so, unnecessary colonoscopies have been avoided in certain patients. Therefore, in this large retrospective study, we aimed to examine the effect of earlier investigation with $\mathrm{CE}$ for inpatients with suspected small bowel bleeding manifesting as melaena or severe iron deficiency anaemia.

\section{Patients and methods}

This was a retrospective study of all inpatient CEs carried out at our tertiary care academic center from March 2005 to March 2017, using a prospectively-designed and continuously maintained database. Data collected were:

- Patient demographics: age, gender

- Relevant past medical history: cardiovascular, liver and/or renal disease; use of antiplatelet and/or anticoagulant medications; any previous episodes of gastrointestinal bleeding;

- Circumstances of admission;

- CE indications and findings;

- Timing of CE relative to admission and prior conventional endoscopies;

- Conventional endoscopies carried out within the past 6 months prior to admission;

- Further investigations and results;

- Patient outcomes, defining follow-up period as the date of last recorded patient contact with local healthcare services, discharge (back) to another health board, or death.

We analyzed inpatients undergoing CE for suspected small bowel bleeding, defined as IDA or melena in patients with negative UGIE, with no other signs or symptoms suggesting lower gastrointestinal tract pathology such as frank rectal bleeding, diarrhea with associated significant weight loss or lower abdominal pain. Over the study period, patients admitted with UGIE-negative IDA or melena underwent CE either following nondiagnostic bidirectional endoscopy (we called these patients Group 1) or following only negative UGIE (Group 2), based on the senior clinician-in-charge's individual investigative pathways.

CE was carried out with one of two commercially-available CE systems, PillCam SB1/2 (Given Imaging Ltd, now Medtronic, Minneapolis, Minnesota, United States) or Mirocam (Intromedic, Seoul, South Korea). Small bowel preparation was dependent on timing of CE relative to UGIE or colonoscopy, as well as the overall patient condition. In general, our center's protocol has been to use 2 L PEG, although an overnight fast alone was sometimes used for frailer patients. If CE was carried out immediately after colonoscopy, additional bowel preparation beyond the $2 \mathrm{~L}$ PEG used for colonoscopy was not given. Simethicone was administered with all CEs; use of prokinetics was guided by evolving practice guidelines and individual patient need [8]. Over this time period, CEs were read and reported by one of three experienced readers based at our center using the relevant proprietary software. Speed and reading conditions varied as per individual preference. Significant CE findings were those deemed causative of the patient's presentation. These includ- ed: vascular lesions (e.g. angioectasias), areas of fresh and ongoing bleeding seen at the time of CE, inflammatory lesions (e. g. ulcers, aphthae and strictures), various enteropathies such as nonsteroidal anti-inflammatory drug-related enteropathy or portal hypertensive enteropathy, and discrete bleeding mass lesions. Over the study period, all CEs carried out at our center have been recorded in a prospectively designed database with the above details noted to be correct at time of CE.

Continuous data are reported as mean \pm standard deviation (SD) or median (range) where appropriate. Statistical analyses were carried out and normality of distributions was tested by plotting histograms using the Analysis Toolpak in Microsoft Excel 2010 (Microsoft Corporation, Redmond, Washington, United States). For normally distributed data, Student's t-test (when $\mathrm{n}<30$ ) or the Z-test (when $\mathrm{n} \geq 30$ ) were used to compare means, whereas the Mann-Whitney U-test was used for data where a normal distribution could not be assumed. The Chisquare test was used to compare proportions for discrete data variables. A $P$ value $<0.05$ was taken to denote statistical significance. No specific institutional ethical approval was required for this study as the data used had been collected in the course of routine patient care; ethical approval has been granted to the unit as a whole for the safe, confidential collection and storage of relevant patient information relating to CE.

\section{Results}

Over the period from March 2005 to March 2017, 170 inpatients underwent CE for suspected small bowel bleeding (104 male, 66 female; mean age $65.8 \pm 17.1$ years). Forty-four patients had IDA and 126 had melena. Mean hemoglobin level $(\mathrm{Hb})$ at presentation was $82.8 \pm 22.4 \mathrm{~g} / \mathrm{L}$. In total, there were 6 incomplete CEs; 2 were retained and required endoscopic or surgical retrieval. Median follow-up time was 31.1 months (range 0.03-121.4 months); however, it must be noted that this was a continuously maintained database and follow-up times depended on the time from CE to data collection for each patient.

Patients were divided into two groups for analysis of outcomes ( $\triangleright$ Fig. 1). Group 1 comprised those with negative bidirectional endoscopy, while Group 2 included those with only negative UGIE. The groups had similar admission Hb, demographics, and medical history; they were also followed up for similar periods of time overall ( $\triangleright$ Table 2 ). Patients in Group 2 were significantly more likely to have been admitted with melena and were also significantly more symptomatic from blood loss at the time of admission. Outcomes and further investigations carried out within the two groups are summarized in $\downarrow$ Table 3.

\section{CE findings and outcomes: Group 1}

In Group 1, there were 95 CEs carried out following negative bidirectional endoscopy. There were significant CE findings in 50 patients, i.e. DY $52.6 \%$. Of these patients, 46 had SB findings; 17 of 46 patients had additional non-SB findings detected by CE in the stomach $(n=9)$, colon $(n=6)$ or both $(n=2)$. Another 4 patients had normal SB but colon findings seen on CE which 
- Table 1 Summary of previous studies on inpatient use of CE.

\begin{tabular}{|c|c|c|c|c|}
\hline Authors, Year & Type of study & CE procedure & Patients & Findings \\
\hline $\begin{array}{l}\text { Robinson et al., } \\
2011[5]\end{array}$ & $\begin{array}{l}\text { Retrospective, } \\
\text { multicenter }\end{array}$ & $\begin{array}{l}\text { PillCam SB2, PEG, } \\
\text { no simethicone, } \\
\text { prokinetics as } \\
\text { indicated }\end{array}$ & $\begin{array}{l}\text { Inpatients: } 167 \\
\text { Outpatients: } 540\end{array}$ & $\begin{array}{l}\text { Significant findings, endoscopic placement, nongastric } \\
\text { passage and incomplete CE more likely in inpatients. } \\
\text { Inpatients had longer GTT, were more likely to be male } \\
\text { and have overt bleeding. }\end{array}$ \\
\hline $\begin{array}{l}\text { Lepileur et al., } \\
2012[6]\end{array}$ & $\begin{array}{l}\text { Retrospective, } \\
\text { multicenter }\end{array}$ & $\begin{array}{l}\text { PillCam M2A, } \\
\text { PEG }\end{array}$ & $\begin{array}{l}\text { Inpatients: } 137 \\
\text { Outpatients: } 774\end{array}$ & $\begin{array}{l}\text { Predictive factors for positive CE: males, > } 60 \text { years, } \\
\text { overt bleeding, inpatients }\end{array}$ \\
\hline $\begin{array}{l}\text { Yazici et al., } \\
2012[7]\end{array}$ & $\begin{array}{l}\text { Retrospective, } \\
\text { single center }\end{array}$ & $\begin{array}{l}\text { PillCam SB, no } \\
\text { laxative prepa- } \\
\text { ration }\end{array}$ & $\begin{array}{l}\text { Inpatients: } 70 \\
\text { Outpatients: } 264\end{array}$ & $\begin{array}{l}\text { Inpatients were older, more likely to have overt bleed- } \\
\text { ing, and active bleeding was more commonly found in } \\
\text { inpatients. } \\
\text { CE completion rate significantly lower in inpatients and } \\
\text { patients with gastrointestinal bleeding; prolonged GTT } \\
\text { and SBTT in inpatients. } \\
\text { Results amplified when looking only at ICU inpatients } \\
\text { vs. general ward patients. }\end{array}$ \\
\hline $\begin{array}{l}\text { Singh et al., } \\
2013[4]\end{array}$ & $\begin{array}{l}\text { Retrospective, } \\
\text { single center }\end{array}$ & $\begin{array}{l}\text { PillCam SB/SB2, } \\
\text { no laxative prep- } \\
\text { aration }\end{array}$ & $\begin{array}{l}\text { Inpatients: } 144 \\
\text { Outpatients: } 116 \\
\text { (all patients having CE } \\
\text { for overt OGIB) }\end{array}$ & $\begin{array}{l}\text { Early use of CE within } 3 \text { days of admission associated } \\
\text { with higher diagnostic yield, therapeutic intervention } \\
\text { rate and reduced length of stay. }\end{array}$ \\
\hline
\end{tabular}

were deemed relevant. Forty-five patients had nondiagnostic CE following negative bidirectional endoscopy. In 31, the SB was reported as normal whereas the other 14 had nonspecific findings thought unlikely to be of clinical significance. The indication for CE was melena in 67 patients and IDA in 28. The proportions of patients with melena and IDA with or without significant CE findings were not significantly different ( $\vee$ Table 3 ).

Therefore, in this group, CE found a total of 16 of 95 (16.8\%) gastric findings which had been missed on initial UGIE. Ten patients had repeat UGIE; in 9 of 10 the UGIE was done to further investigate or manage lesions seen on CE while 1 was a "second look." There were missed colon findings in 12 of 95 (12.6\%) patients, of whom three required repeat colonoscopy for APC; the others were managed conservatively for confirmed or likely diverticular bleeds. A further three patients had repeat colonoscopies due to rebleeding and/or ongoing bleeding, i.e. 6 of 95 patients had repeat colonoscopies. Two patients underwent computed tomography (CT) colonography following CE. Double balloon enteroscopy (DBE) was performed on seven patients in this group to manage SB lesions seen on CE. Seven patients required surgery to investigate discrete lesions seen on CE $(n=3)$ or to manage continued bleeding $(n=4)$.

\section{CE findings and outcomes: Group 2}

In Group 2, 75 CEs were performed in patients who had negative UGIE only, with a DY of 39 of 75 (52.0\%). In the 39 patients with significant CE findings, 6 of 39 had normal SB but significant non-SB findings in the stomach $(n=2)$ and colon $(n=4)$. Of the 33 patients with SB findings on CE, 9 of 33 had additional non-SB findings in the stomach $(n=3)$, colon $(n=2)$ or both $(n=$ 4). Of the 36 patients with nondiagnostic CE, the SB was reported as normal in 28. Three patients in this subgroup had additional non-SB findings (which were considered insignificant): two in the stomach and one patient with findings in both stomach and colon. The indication for CE was melena in 59 patients and IDA in 16. Patients with nondiagnostic CE findings were significantly more likely to have undergone CE for melaena rather than IDA, compared to patients with significant CE findings ( $P=$ 0.03).

There were 12 of 75 (16.0\%) gastric findings missed by initial UGIE. Ten patients underwent repeat UGIE. Six UGIEs were done to target lesions seen on CE ( 3 of these were push enteroscopies to reach the duodenum). Eleven of 75 (14.7\%) patients had new colon findings; all these findings were AVMs and/or colonic bleeding. Overall in this group, 25 patients underwent colonoscopy following CE. Seven colonoscopies were done to target lesions seen on CE while the remainder were carried out in patients experiencing continued bleeding or symptoms. Fourteen of 25 colonoscopies found likely causes for the patients' presentations; notably, one patient was found to have a colon adenocarcinoma. In the patients with negative colonoscopies, most were managed conservatively with spontaneous resolution of bleeding in six; in two patients repeat UGIE found the likely sources of blood loss. One patient had CT colonography following normal CE with no cause found.

Nine patients underwent DBE to further investigate discrete lesions seen on CE ( $n=3)$, manage SB angioectasias $(n=3)$ and further investigate/manage an area of active SB bleeding seen on CE $(n=3)$. Four patients had surgery for lesions seen on CE.

\section{Comparison of colon investigations per episode of gastrointestinal bleeding between the two groups}

In Group 1, a total of 103 colon investigations (colonoscopies and CT colonographies) were performed for 95 inpatient episodes of suspected small bowel bleeding, giving a rate of 1.08 colon investigations per episode. The overall diagnostic yield of 


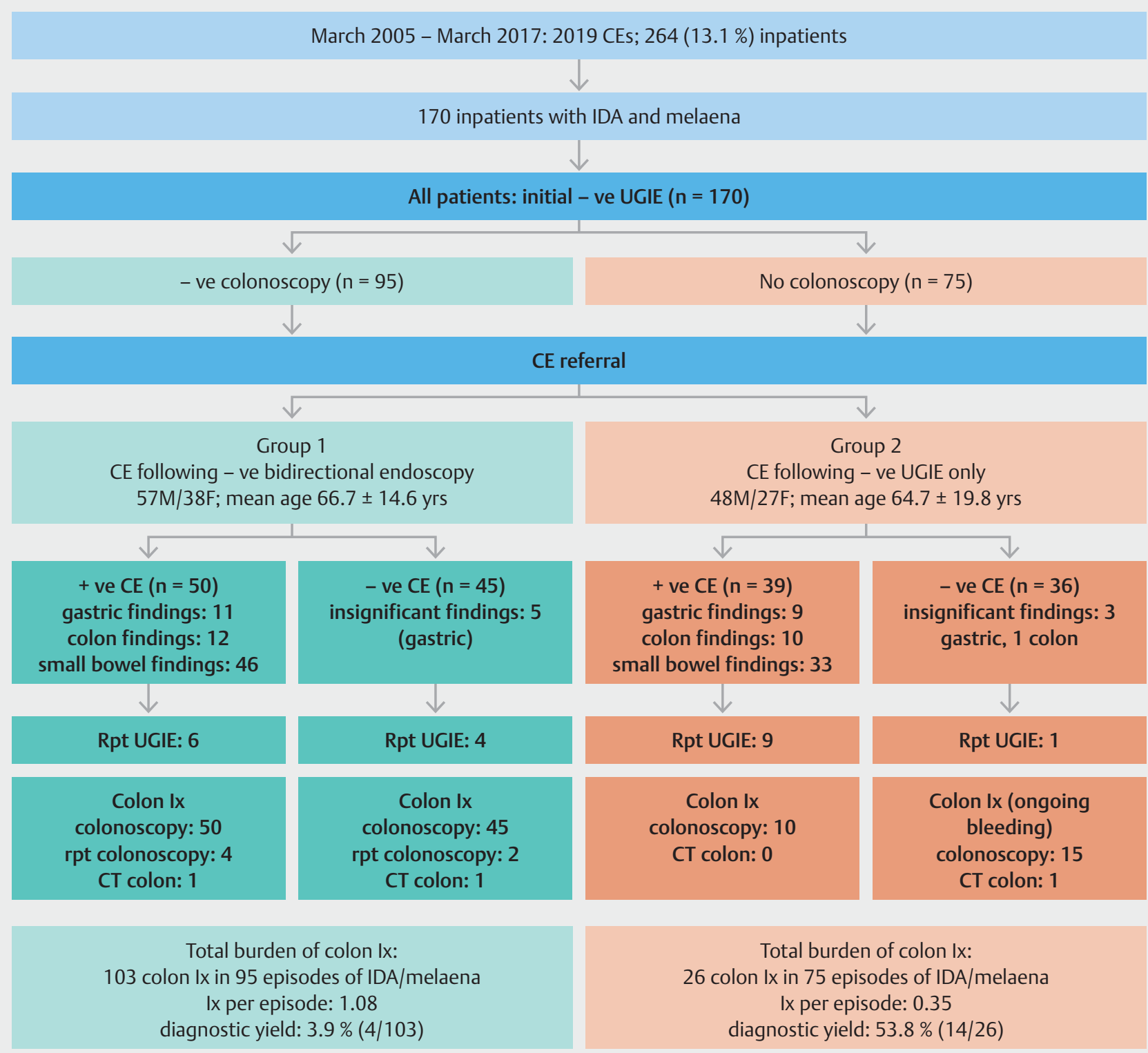

Fig. 1 Flow diagram showing investigative pathways in our group of inpatients with IDA/melena. + ve positive; -ve negative; Ix investigations; rpt repeat.

these colon investigations was 3.9\%. Using the alternative approach in Group 2, 26 colon investigations were performed for 75 inpatient episodes of suspected small bowel bleeding, i.e. 0.35 colon investigations were carried out per episode. The diagnostic yield in this group was $53.8 \%$.

\section{Length of time between admission and CE}

Examining only data from patients admitted for gastrointestinal bleeding (excluding elective admissions and patients with unrelated initial presentations who developed gastrointestinal bleeding during their hospital stay), patients in Group 2, undergoing CE following negative UGIE only, had significantly shorter mean times from admission to CE compared to patients in Group 1 (5.08 \pm 3.80 vs. $6.38 \pm 3.80$ days; $P=0.02)$ and shorter overall admission length $(10.5 \pm 9.58$ vs. $12.5 \pm 11.4$ days; $P=$ 0.04). This was despite patients in Group 2 being more symptomatic of blood loss at the time of admission, including a greater proportion of patients displaying hemodynamic compromise when admitted (14/75 patients in Group 2 vs. 4/95 patients in Group $1 ; P=0.002)$.

\section{Discussion}

In this study, we found that the earlier use of CE for inpatients with melena or IDA following negative UGIE reduces the need for subsequent colonoscopy and shortens admission times. Previous data from Singh et al. [4] in a group of 144 inpatients showed that earlier use of CE (within 3 days of admission) was 
- Table 2 Comparison of patient characteristics between patients undergoing CE following negative bidirectional endoscopy and patients undergoing CE following negative UGIE only.

\begin{tabular}{|c|c|c|c|}
\hline & $\begin{array}{l}\text { Group 1: CE after negative } \\
\text { bidirectional endoscopy }\end{array}$ & $\begin{array}{l}\text { Group 2: CE after negative } \\
\text { UGIE only }\end{array}$ & $P$ value \\
\hline Total number & 95 & 75 & \\
\hline $\mathrm{M} / \mathrm{F}(\%)$ & $57 \mathrm{M}(60 \%) / 38 \mathrm{~F}(40 \%)$ & $48 \mathrm{M}(64 \%) / 27 \mathrm{~F}(36 \%)$ & 0.59 \\
\hline Age; years (mean \pm SD) & $66.7 \pm 14.6$ & $64.7 \pm 19.8$ & 0.46 \\
\hline \multicolumn{4}{|l|}{ РMH } \\
\hline Liver disease (\%) & $15(15.8)$ & $11(14.7)$ & 0.84 \\
\hline Cardiovascular disease (\%) & $46(48.4)$ & $29(38.7)$ & 0.20 \\
\hline On anticoagulants/ antiplatelets (\%) & $\begin{array}{l}37(38.9) \\
24 \text { on anticoagulants } \\
17 \text { on antiplatelets }\end{array}$ & $\begin{array}{l}23(30.7) \\
10 \text { on anticoagulants } \\
13 \text { on antiplatelets }\end{array}$ & 0.26 \\
\hline Renal disease (\%) & $10(10.5)$ & $9(12.0)$ & 0.76 \\
\hline Previous episode/s of gastrointestinal bleeding (\%) & $28(29.5)$ & $24(32.0)$ & 0.72 \\
\hline \multicolumn{4}{|l|}{ Admission details } \\
\hline Melena (\%) & $48(50.5)$ & $50(66.7)$ & 0.03 \\
\hline IDA only (\%) & $28(30.4)$ & $16(21.3)$ & 0.23 \\
\hline Other (\%) & $19(20.0)$ & $9(12.0)$ & 0.16 \\
\hline Symptomatic from blood loss (\%) & $31(32.6)$ & $38(50.7)$ & 0.02 \\
\hline $\begin{array}{l}\text { Hemodynamic compromise at time of admission (\%) } \\
\text { (collapse, hypotension, tachycardia) }\end{array}$ & $4(4.2)$ & $14(18.7)$ & 0.002 \\
\hline Admission $\mathrm{Hb} ; \mathrm{g} / \mathrm{L}($ mean $\pm \mathrm{SD})$ & $82.8 \pm 20.7$ & $82.9 \pm 24.6$ & 0.98 \\
\hline Length of time from admission to $\mathrm{CE}$; days (mean $\pm \mathrm{SD})^{1}$ & $6.38 \pm 3.80(n=68)$ & $5.08 \pm 3.80(n=66)$ & 0.02 \\
\hline Total length of admission; days (mean \pm SD) ${ }^{1}$ & $12.5 \pm 11.4(n=68)$ & $10.5 \pm 9.58(n=66)$ & 0.04 \\
\hline Follow-up time after $\mathrm{CE}^{2}$; months (mean $\pm \mathrm{SD}$ ) & $37.9 \pm 31.5$ & $35.8 \pm 31.9$ & 0.62 \\
\hline \multicolumn{4}{|c|}{$\begin{array}{l}\text { CE capsule endoscopy; Hb hemoglobin; IDA iron deficiency anemia; PMH past medical history; SD standard deviation } \\
1 \text { These calculations include only data from patients admitted specifically for IDA/melena; i. e. excluding patients admitted electively or with unrelated initial pre- } \\
\text { sentations. }\end{array}$} \\
\hline
\end{tabular}

associated with higher DY, rates of therapeutic intervention and decreased length of stay. Similarly, our patients who underwent CE earlier in the diagnostic pathway also had a significantly shorter mean length of stay by about 2 days $(P=0.04)$. This translates to potentially significant cost savings or at least increased patient turnover and therefore capacity, especially important in large hospitals with high patient caseload. In a 2006 study by Marmo et al. [9], soon after the introduction of commercial CE, patients undergoing CE for obscure gastrointestinal bleeding (OGIB) required a mean of 1.7 hospital admissions to reach a positive diagnosis, with a mean of 15.5 days of hospital stay; $42 \%$ had more than one colonoscopy; $44.6 \%$ had two or more UGIEs. Hospital admissions were the biggest cause of resource utilization in their group of patients, followed closely by colonoscopies and UGIEs. We do, however, acknowledge that cost savings would vary between countries and healthcare systems as the cost of CE may not be adequately reimbursed at some centers.
From our experience, the reasons for the shortened length of stay in patients in Group 2 could be related to the additional time required to perform both upper and lower gastrointestinal endoscopies before making the decision to proceed to CE. Therefore, early use of inpatient CE was useful in guiding the choice of the next most appropriate route of investigation or management, as well as aiding the decision whether to proceed with these investigations and interventions urgently or following discharge. Similarly, in previous studies where CE was used acutely or semi-acutely to investigate gastrointestinal bleeding ( $\triangleright$ Table 4), CE findings showed good correlation with subsequent UGIE where CE was performed as a first-line investigation before any other endoscopies [10-14]; CE carried out after endoscopic imaging was effective in directing the subsequent route of investigation [15-21].

These findings are corroborated by our study. Patients in Group 1 underwent 3.13 as many colon investigations per admission for IDA or OGIB compared to those in Group 2; how- 
- Table 3 Investigations and management in our group of inpatients with IDA/melena.

\begin{tabular}{|c|c|c|c|c|}
\hline \multirow[b]{2}{*}{ CE findings } & \multicolumn{2}{|c|}{$\begin{array}{l}\text { Group 1: } \\
\text { CE following -ve bidirectional endoscopy }\end{array}$} & \multicolumn{2}{|c|}{$\begin{array}{l}\text { Group 2: } \\
\text { CE following -ve UGIE only }\end{array}$} \\
\hline & + ve CE & -ve CE & + ve CE & -ve CE \\
\hline Number of patients (\%) & $50(52.6)$ & $45(47.4)$ & $39(52.0)$ & $36(48.0)$ \\
\hline Incomplete CEs (\%) & \multicolumn{2}{|l|}{$3(3.2)$} & \multicolumn{2}{|l|}{$3(4.0)$} \\
\hline \multicolumn{5}{|l|}{ UGIE and colonoscopy } \\
\hline Missed findings on initial UGIE (\%) & $11(22.0)$ & $\begin{array}{l}5(11.1) \\
\text { all insignificant }\end{array}$ & $9(23.1)$ & $\begin{array}{l}3(8.3) \\
\text { all insignificant }\end{array}$ \\
\hline $\begin{array}{l}\text { Missed findings on initial colonoscopy } \\
\text { (Group 1) (\%) }\end{array}$ & $12(24.0)$ & - & \multicolumn{2}{|l|}{ NA } \\
\hline Colon findings on CE (Group 2) (\%) & \multicolumn{2}{|l|}{ NA } & $10(25.6)$ & $\begin{array}{l}1(2.8) \\
\text { insignificant }\end{array}$ \\
\hline Repeat UGIEs (\%) & $6(12.0)$ & $4(8.9)$ & $9(23.1)$ & $1(2.8)$ \\
\hline $\begin{array}{l}\text { Total number of colon procedures/lx } \\
\text { carried out }\end{array}$ & $\begin{array}{l}\text { Initial colonoscopy: } 50 \\
\text { Repeat colonoscopy: } 4 \\
\text { CT colon: } 1 \\
\text { Total: } \mathbf{5 5}\end{array}$ & $\begin{array}{l}\text { Initial colonoscopy: } 45 \\
\text { Repeat colonoscopy: } 2 \\
\text { CT colon: } 1 \\
\text { Total: } \mathbf{4 8}\end{array}$ & $\begin{array}{l}\text { Initial colonoscopy: NA } \\
\text { Colonoscopy: } 10 \\
\text { CT colon: } 0 \\
\text { Total: } \mathbf{1 0}\end{array}$ & $\begin{array}{l}\text { Initial colonoscopy: NA } \\
\text { Colonoscopy: } 15 \\
\text { CT colon: } 1 \\
\text { Total: } \mathbf{1 6}\end{array}$ \\
\hline Total burden of colon Ix & \multicolumn{2}{|c|}{103 colon Ix for 95 episodes } & \multicolumn{2}{|c|}{26 colon Ix for 75 episodes } \\
\hline Diagnostic yield of colon Ix & \multicolumn{2}{|l|}{$3.9 \%(4 / 103)$} & \multicolumn{2}{|l|}{$53.8 \%(14 / 26)$} \\
\hline \multicolumn{5}{|c|}{ Other Ix and/or management following CE } \\
\hline DBE (\%) & $7(14.0)$ & - & $9(23.1)$ & - \\
\hline CT angiography (\%) & $5(10.0)$ & $3(6.7)$ & $1(2.6)$ & $2(5.6)$ \\
\hline Repeat CE (\%) & - & - & $2(5.1)$ & - \\
\hline Surgery (\%) & $5(10.0)$ & $2(4.4)$ & $4(10.3)$ & - \\
\hline
\end{tabular}

ever, in Group 2, use of CE earlier in the diagnostic pathway increased the DY of the resulting colonoscopies. Moreover, no adverse outcomes related to colon pathology were reported in those patients who did not have colon investigations following CE. Notably, our study reports a higher completion rate with six incomplete CEs and only two retained capsules in 170 inpatient CEs, compared to previously quoted inpatient completion rates of $50 \%$ by Dunnigan et al. [22] and 68.6\% from Yazici et al. [7]. This therefore implies that in selected patients with IDA or melena, without frank rectal bleeding or other such signs or symptoms suggesting lower gastrointestinal tract pathology, CE could be used as a diagnostic or screening tool following initial UGIE. The results of CE were able to assist clinicians in determining the next most appropriate investigation, with no missed diagnoses in our group of patients.

The advantages of such an approach are appealing as a significant proportion of patients with gastrointestinal bleeding or suspected gastrointestinal bleeding have been shown to require multiple investigations. Woodward et al. conducted an analysis on the length of endoscopic workup in a large group of 451,470 patients presenting with gastrointestinal bleeding [23]. A quarter of these patients required more than one proce- dure to investigate and/or manage gastrointestinal bleeding, with an average of 2.4 procedures per patient. In particular, patients with anemia were the least likely to be managed with a single procedure, with $20 \%$ and $21 \%$ of these patients requiring further UGIEs and colonoscopies, respectively. Similarly, in a 2015 study, Sonnenberg modelled test sequences in patients with gastrointestinal bleeding, and found an average of 2.7 procedures performed per patient, with a significant $5 \%$ of patients requiring more than six procedures [24].

An alternative approach to $C E$ is for patients with ongoing gastrointestinal bleeding to undergo repeat UGIE and colonoscopy; this would be supported by the incidence of "missed" upper and lower gastrointestinal findings seen in our group. This approach is in line with work by Fry et al. [25], but on the other hand, is not suggested by the current guidelines, and would be limited by increased investigative burden and poor patient acceptability. Furthermore, the current convention of performing colonoscopy before CE is based on older, possibly now less-supported data that suggest the small bowel is the bleeding source in $10 \%$ of gastrointestinal bleeding [26]. With the technological advances now available, we would suggest that the increasing accessibility of CE as a diagnostic test is combined with com- 


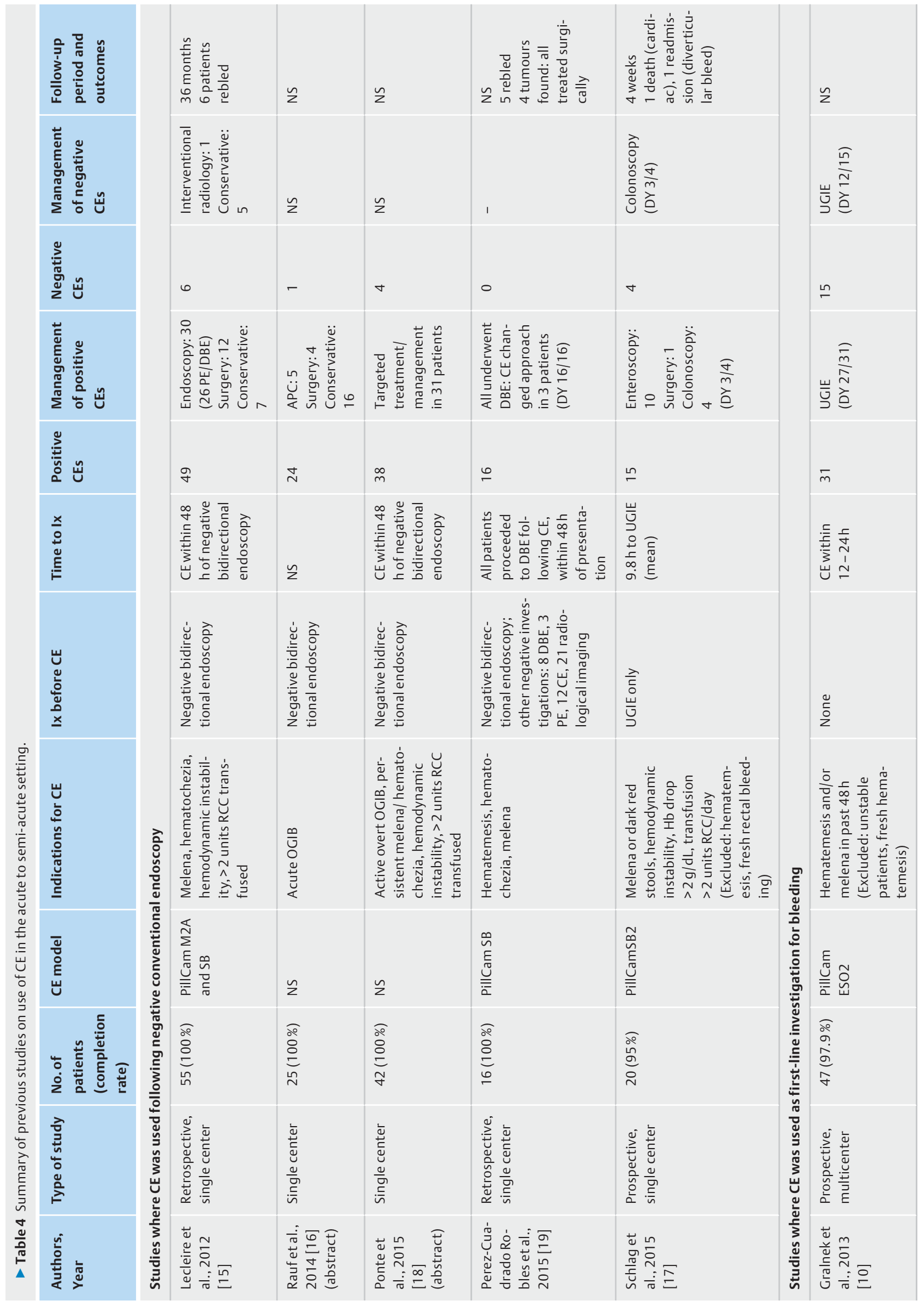




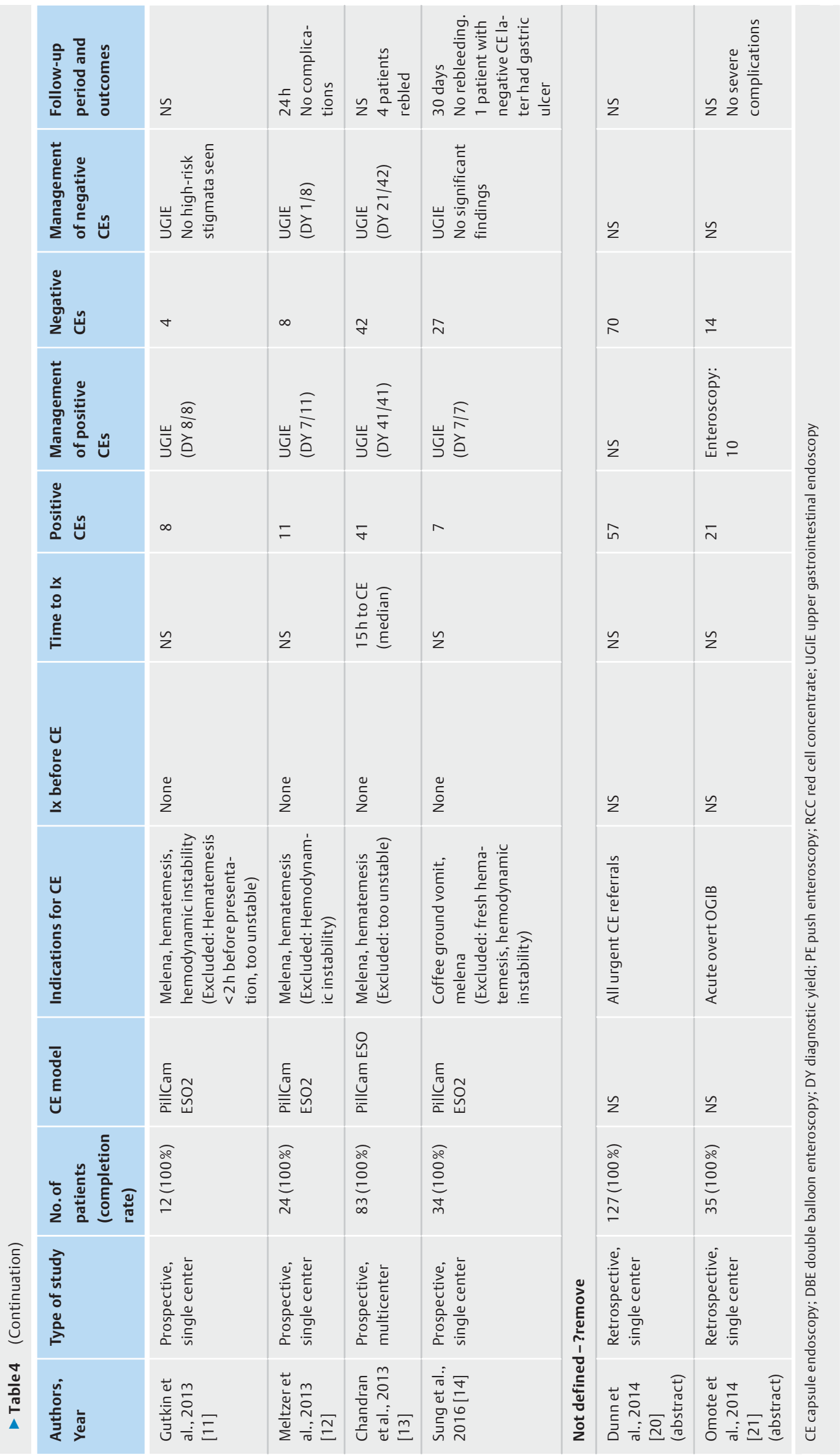


prehensive clinical assessment to ensure an appropriate and timely choice of investigation for patients with gastrointestinal bleeding.

Limitations of this study stem largely from its retrospective design including missing data, dependence on good prior recordkeeping and the possible effects of advances in CE technology since its introduction to clinical practice. However, although image quality may have improved over the study period, the main finding of concern in patients with gastrointestinal bleeding is localization of blood within the gastrointestinal tract rather than detailed lesion definition; this is an obvious finding where technological improvement may not have had as great an impact. Furthermore, our center's data date from 2005, when CE had already been approved for conventional clinical use, with acceptable image quality from the first models which we had used. Similarly, our center had started using PEG for bowel preparation at an early stage, almost from the beginning of the capsule service, even though official guidelines had not been standardized then; most of the patients in our group received similar bowel preparation throughout the study period.

Another limitation stemming from the retrospective study design is that choice of investigative pathway and CE timing in our patients was determined by consultant preference. Despite this, the demographics and admission data suggest that the two groups were comparable. Given that melena was more often the indication for CE in Group 2, our results would also suggest that such patients with melena and negative UGIE are more likely to benefit from earlier use of CE. Although this approach seems logical, in routine clinical practice, most centers currently reserve use of CE until a negative colonoscopy has occurred. Furthermore, and despite the recognized disadvantages of a retrospective study, such a study has the benefit of a large patient group, longer follow-up times and accurate reflection of "real world" experience.

\section{Conclusion}

In conclusion, inpatient CE for IDA or melena had a diagnostic yield of $52.3 \%$ at our center. In such patients, use of CE earlier in the investigative pathway significantly reduced the number of colonic investigations performed without compromising clinical outcomes. This has the potential to improve the patient experience by reducing the number of negative invasive procedures. We found that earlier use of CE also shortened hospital stays. Our findings inspire confidence in earlier use of CE in inpatients with IDA or melena in the absence of signs and symptoms suggestive of colonic pathology.

\section{Competing interests}

\section{None}

\section{References}

[1] Gerson LB. Small Bowel bleeding: updated algorithm and outcomes. Gastrointest Endosc Clin N Am 2017; 27: 171 - 180

[2] Koulaouzidis A, Rondonotti E, Giannakou A et al. Diagnostic yield of small-bowel capsule endoscopy in patients with iron-deficiency anemia: A systematic review. Gastrointest Endosc 2012; 76: 983 - 992

[3] Yung DE, Koulaouzidis A, Avni T et al. Clinical outcomes of negative small-bowel capsule endoscopy for small-bowel bleeding: a systematic review and meta-analysis. Gastrointest Endosc 2017; 85: 305- 317

[4] Singh A, Marshall C, Chaudhuri B et al. Timing of video capsule endoscopy relative to overt obscure GI bleeding: Implications from a retrospective study. Gastrointest Endosc 2013; 77: 761 - 766

[5] Robinson CA, Jackson C, Condon D et al. Impact of inpatient status and gender on small-bowel capsule endoscopy findings. Gastrointest Endosc 2011; 74: 1061 - 1066

[6] Lepileur L, Dray X, Antonietti M et al. Factors associated with diagnosis of obscure gastrointestinal bleeding by video capsule enteroscopy. Clin Gastroenterol Hepatol 2012; 10: 1376 - 1380

[7] Yazici C, Losurdo J, Brown MD et al. Inpatient capsule endoscopy leads to frequent incomplete small bowel examinations. World J Gastroenterol 2012; 18: 5051 - 5057

[8] Koulaouzidis A, Giannakou A, Yung DE et al. Do prokinetics influence the completion rate in small-bowel capsule endoscopy? A systematic review and meta-analysis Curr Med Res Opin 2013; 29: 1171 - 1185

[9] Marmo R, Rotondano G, Rondonotti E et al. Capsule enteroscopy vs. other diagnostic procedures in diagnosing obscure gastrointestinal bleeding: a cost-effectiveness study. Eur J Gastroenterol Hepatol 2007; 19: $535-542$

[10] Gralnek I, Ching J, Maza I et al. Capsule endoscopy in acute upper gastrointestinal hemorrhage: a prospective cohort study. Endoscopy 2013; 45: $12-19$

[11] Gutkin E, Shalomov A, Hussain S et al. Pillcam $\mathrm{ESO}^{\circledR}$ is more accurate than clinical scoring systems in risk stratifying emergency room patients with acute upper gastrointestinal bleeding. Therap Adv Gastroenterol 2013; 6: 193-198

[12] Meltzer AC, Ali MA, Kresiberg RB et al. Video capsule endoscopy in the emergency department: A prospective study of acute upper gastrointestinal hemorrhage. Ann Emerg Med 2013; 61: 438-443

[13] Chandran S, Testro A, Urquhart P et al. Risk stratification of upper GI bleeding with an esophageal capsule. Gastrointest Endosc 2013; 77: $891-898$

[14] Sung JJ, Tang RS, Ching JY et al. The use of capsule endoscopy in the emergency department as a triage of patients with GI bleeding. Gastrointest Endosc 2016; 84: $907-913$

[15] Lecleire S, Iwanicki-Caron I, Di-Fiore A et al. Yield and impact of emergency capsule enteroscopy in severe obscure-overt gastrointestinal bleeding. Endoscopy 2012; 44: $337-342$

[16] Rauf A, Arora A, Tyagi P et al. Capsule endoscopy: Role in acute obscure gastrointestinal bleed. Indian J Gastroenterol 2014; 33: A35

[17] Schlag C, Menzel C, Nennstiel S et al. Emergency video capsule endoscopy in patients with acute severe Gl bleeding and negative upper endoscopy results. Gastrointest Endosc 2015; 81: 889-895

[18] Ponte A, Pinho R, Rodrigues A et al. Diagnostic yield and therapeutic impact of emergency capsule enteroscopy in active-overt obscure gastrointestinal bleeding. United Eur Gastroenterol Journal 2015; 3: A212

[19] Pérez-Cuadrado Robles E, Bebia Conesa P, Esteban Delgado P et al. Emergency double-balloon enteroscopy combined with real-time viewing of capsule endoscopy: A feasible combined approach in acute overt-obscure gastrointestinal bleeding? Dig Endosc 2015; 27: 338 344 
[20] Dunn S, Butt F, Bevan R et al. Is there a role for urgent small bowel video capsule endoscopy? United Eur Gastroenterol J 2014; 2: A507

[21] Omote S, Toyokawa T, Horii J et al. Efficiency and safety of immediate capsule endoscopy after acute obscure gastrointestinal bleeding. J Gastroenterol Hepatol 2014; 29: 170

[22] Dunnigan M, Fenkel JM, Miller RR et al. Incomplete Small Bowel Examination During Wireless Capsule Endoscopy Is More Common in Inpatients. Gastrointest Endosc 2007; 65: AB165

[23] Woodward Z, Williams JL, Sonnenberg A. Length of endoscopic workup in gastrointestinal bleeding. Eur J Gastroenterol Hepatol 2016; 28: $1166-1171$
[24] Sonnenberg A. Modeling lengthy work-ups in gastrointestinal bleeding. Clin Gastroenterol Hepatol 2015; 13: 433-439

[25] Fry LC, Bellutti M, Neumann $\mathrm{H}$ et al. Incidence of bleeding lesions within reach of conventional upper and lower endoscopes in patients undergoing double-balloon enteroscopy for obscure gastrointestinal bleeding. Aliment Pharmacol Ther 2009; 29: $342-349$

[26] Gerson LB, Fidler JL, Cave DR et al. ACG Clinical Guideline: Diagnosis and management of small bowel bleeding. Am J Gastroenterol 2015; 110: $1265-1287$ 